\title{
Characterizing and following eddies in Drake Passage
}

\author{
Gómez-Enri, J. \\ Applied Physics Department \\ University of Cadiz \\ Puerto Real (Cadiz), Spain \\ jesus.gomez@uca.es
}

\author{
Navarro, G. \\ Instituto de Ciencias Marinas de Andalucia \\ CSIC \\ Puerto Real (Cadiz), Spain \\ gabriel.navarro@icman.csic.es
}

\author{
Quartly, G. D. \\ Laboratory for Satellite Oceanography \\ Southampton Oceanography Centre, Southampton \\ Southampton, United Kingdom \\ gdq@noc.soton.ac.uk \\ Villares, P. \\ Applied Physics Department \\ University of Cadiz \\ Puerto Real (Cadiz), Spain \\ pilar.villares@uca.es
}

\begin{abstract}
Drake Passage, the gap between South America and Antarctica, is a very energetic region, with strong currents and numerous eddies. These eddies are important for mixing waters across the main three fronts, and for affecting the biological productivity in the region. We use weekly maps of color images, sea level anomaly and geostrophic velocities to characterize physical and biological activity in the region surrounding Drake Passage. In particular, we note that the largest eddy kinetic energy occurs to the east of the passage and is principally in the area bounded by the mean Subantarctic Front (SAF) and the mean Polar Front, whilst the biological productivity is highest in coastal regions, with the SAF acting as a clear southern boundary. In a number of cases, cyclonic eddies detected by altimetry also show a strong signature in ocean color. Regular XBT (eXpendable BathyThermograph) surveys provide information on sub-surface structure, confirming the altimetric identification of features and showing that they often contain water masses originating from the other side of the front.
\end{abstract}

Keywords-component; eddies; altimetry; sea level anomaly chlorophyll concentration, XBT, Drake Passage

\section{INTRODUCTION}

The general circulation in Drake Passage (DP) and its surrounding area is described by many papers [e.g. 1-3]. It consists of three major fronts - Subantarctic, Polar and Southern Antarctic Circumpolar Fronts (SAF, PF and SACCF, respectively, in Fig. 1) — with eastward flow concentrated along each. There is also evidence of a small intermittent westward current between SAF and PF at approximately $58^{\circ} \mathrm{S}$ [1]. Using a combination of altimetry, hydrography and current data, [3], estimated the surface geostrophic currents in DP and analyzed the possible origin of the intermittent westward flow observed, suggesting that the topography is playing a major role, instead of the instabilities in the current suggested previously by [2].

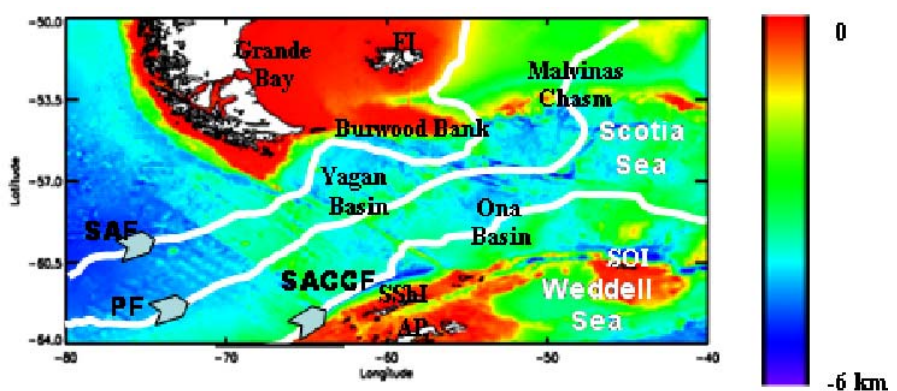

Fig. 1 Bathymetry of study region and mean position of fronts (SAF, PF \& SACCF) overlaid.

The combination of remote sensing data from different platforms has been shown to be a valuable tool in the monitoring of biological activity. The characterization of active regions in the study area has important implications for resource management and conservation [4 and references therein]. Also, eddies contribute to transport biogeochemical properties from coastal areas into deep waters in the DP, where the coastal margins play an important role in the global carbon cycle [5]. Recent studies in the southern southwest Atlantic [6] combined altimeter Sea Level Anomaly maps (SLA), Seaviewing Wide Field-of-view Sensor images (SeaWiFS) and insitu measurements. They analyzed the eddy activity on the northeast side of DP and concluded the necessity of addressing the mesoscale eddies as a mechanism of transport of properties and its influence on the regional circulation. They concluded that the probable origin of these eddies was partial blocking of the Antarctic Circumpolar Current (ACC) by submarine topographic features. Eddies are generated east of DP, and interact with each other following a general path toward northeast (NE). Analysis of the seasonal and interannual variability in SeaWiFS-derived chlorophyll on the western South Atlantic shelf [4] demonstrated the benefits of using ocean-color data to characterize wide and remote marine ecosystems. Several authors [e.g. 7, 8] described the spatial 
and temporal patterns of the surface chlorophyll concentration and primary rates in relation to the Antarctic Polar Front (PF).

We present in this work a short description of the datasets used (section II and III) for the analysis of the mesoscale variability in DP and its surrounding area, combining information from two different platforms: altimeter and ocean color images and in situ data. The main objective is to show the possibilities that these two satellite datasets may offer for the tracking and characterization of eddies associated to biological features (section IV). The conclusions and final remarks will be summarized in the last section.

\section{SATELLITE DATA}

We used three different types of satellite data; these are described below.

\section{A. Altimetry}

For altimetry data we used the DUACS product distributed by Aviso (http://www.aviso.oceanobs.com). We chose the high-resolution "Upd" product, which uses all available altimeters [9], as the mesoscale variability can be much better mapped using more than just the 2 altimeters present in the "Ref" product [10]

We used weekly maps of sea level anomaly (SLA) and zonal/meridional geostrophic velocities, and also a product called "absolute dynamics topography" (ADT) which has an estimate of the mean flow field added to each SLA map.

The eddy variability is usually described in terms of rms of the SLA data. Note that this measurement contains large-scale signals that may interfere in the eddy characterization. The estimation of zonal/meridional geostrophic velocities from SLA acts as a high-pass filter, being more representative of these mesoscale signals [11]. Assuming a geostrophic balance and isotropic conditions [12], the cross-track geostrophic variance is equivalent to the Eddy Kinetic Energy (EKE); although this approximation is only valid at mid and high latitudes [9]. Thus estimates of mean EKE are used here to depict the general mesoscale variability in the study area, instead of the r.m.s. SLA. Fig. 2a shows the mean EKE (climatology map) using the whole time period of the available altimeter data (October 1992 - December 2005). EKE ranges between 0 and $500 \mathrm{~cm}^{2} / \mathrm{s}^{2}$, with a mean value for the whole area of $135 \mathrm{~cm}^{2} / \mathrm{s}^{2}$. EKE reaches its largest values inside the limits of SAF and PF, particularly in the Yagan Basin, and eastward of Burwood Bank (Fig. 1).

\section{B. Chlorophyll concentration}

We acquired chlorophyll data from NASA's Goddard Space Flight Center (GSFC) (see ftp://oceans.gsfc.nasa.gov). The specific products were SeaWiFS v5.1 data and MERGED product (MODIS + SeaWiFS), available as weekly Standard Mapped Images (SMI) for the period 1998 to 2005. These were global datasets at $9 \times 9 \mathrm{~km}$ resolution, which we subsampled to the region of interest.
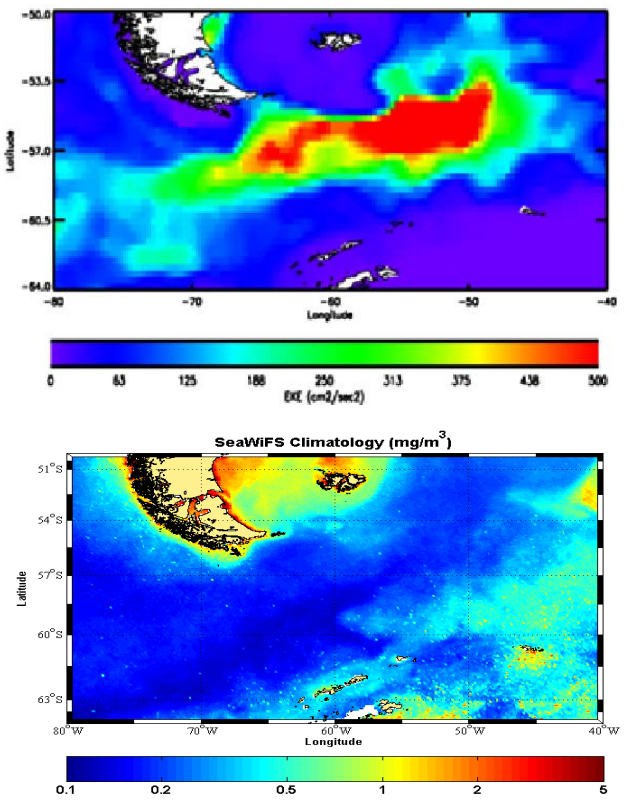

Fig. 2. Climatology maps of a) eddy kinetic energy from altimetry $\left(\mathrm{cm}^{2} / \mathrm{s}^{2}\right)$ and b) mean chlorophyll distribution from SeaWiFS $\left(\mathrm{mg} / \mathrm{m}^{3}\right)$.

Fig. $2 \mathrm{~b}$ shows the climatology of the chlorophyll concentration (in $\mathrm{mg} / \mathrm{m}^{3}$ ) based on eight years of SeaWiFS ocean-color data (1998 - 2005). From the analysis of this map we extract information regarding the characteristic patterns of the biomass variability, identifying areas of potential biological activity. The biomass concentration ranges between 0.1 and 5 $\mathrm{mg} / \mathrm{m}^{3}$. The whole area is characterized by low chlorophyll concentrations, especially in the zones in which the higher EKE variability is found between the SAF and PF fronts. Areas of high chlorophyll concentration are found to the north of the Falkland Islands (FI) and along the South American coast (Grande Bay). In addition, phytoplankton blooms occurs during austral summer season with maximum values in the coastal/shelf waters off South America [4, 8]. Some areas of persistent high productivity are noted in the vicinity of the South Orkney Islands (SOI), South Shetland Islands (SShI) and Antarctic Peninsula (AP) and in the eastern aperture of the Malvinas Chasm (Fig. 1). These could be related to frontal systems or zones with sea-ice melt, both of which increase the nutrient concentration and thus may stimulate phytoplankton blooms [8 and references therein].

\section{EXPENDABLE BATHYTHERMOGRAPH (XBT) DATA}

A hydrographic section was run across Drake Passage between $13^{\text {th }}$ and $15^{\text {th }}$ June 2001, with 68 XBTs deployed. Personnel at Scripps applied quality control tests to the data and regridded them in depth to provide temperature values for the top $900 \mathrm{~m}$ at a resolution of $10 \mathrm{~m}$. The location of this section (in relation to contemporaneous altimeter data) is shown in Fig. 3. Near $57.2^{\circ} \mathrm{S}$ the transect crosses a relative low in topography, indicative of a cyclonic (clockwise) eddy. 


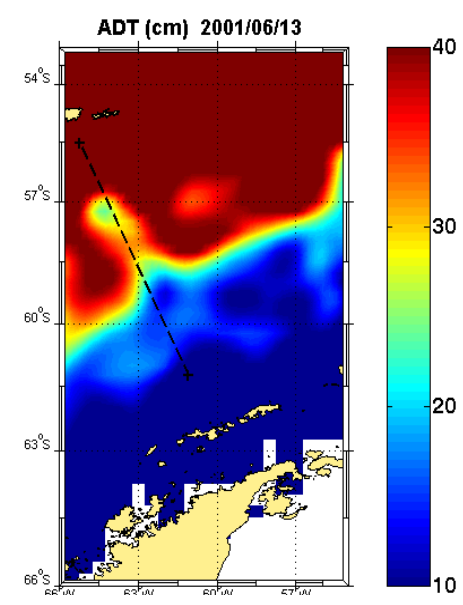

Fig. 3. Satellite data of Absolute dynamic topography $(\mathrm{cm})$ showing location of XBT transect described in Fig 4.

Fig. $4 \mathrm{~b}$ shows the depth structure of the temperatures across this section. (Note, the depth is $\sim 4000 \mathrm{~m}$ for $63^{\circ}-56^{\circ} \mathrm{S}$; the white areas represent missing data due an XBT failing to give information throughout its drop). Of particular interest is the feature at $57.3^{\circ} \mathrm{S}$, with a core of cold water at $150-200 \mathrm{~m}$. This matches very well the position of the low in topography seen in Fig. 3. To be gravitationally stable, this water must also be much fresher than its surroundings, and thus may be concluded to originate from the surface waters south of $60^{\circ} \mathrm{S}$. The top panel (Fig. 4a) shows the temperature at two particular depths; the blue line represents values at the depth of the cold core, whilst the red line shows a 'surface' temperature as might be recorded by satellites (these actually measure the skin of the ocean surface). Note that south of $60^{\circ} \mathrm{S}$ the surface is colder than the waters at depth. For this particular section a thermal front as would be seen by a satellite coincides with that at depth; this is not always the case.

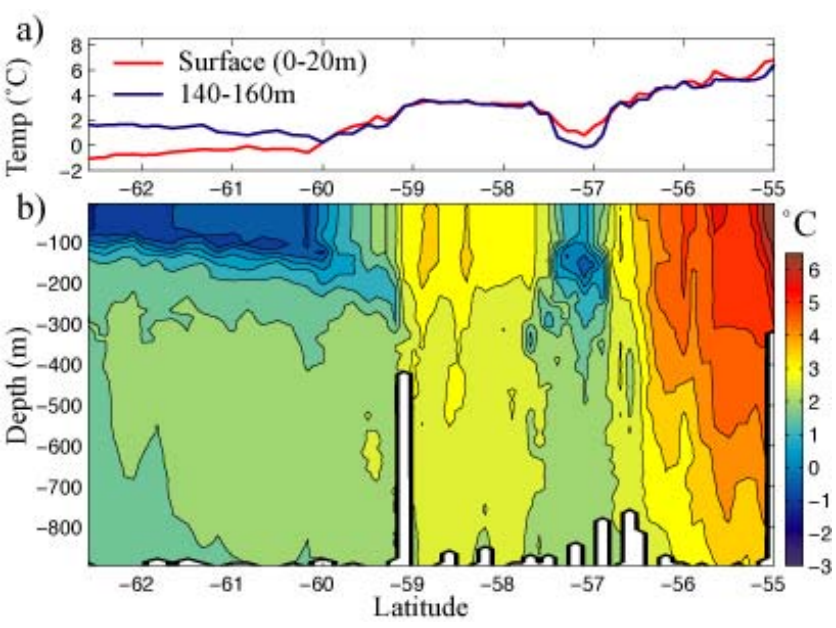

Fig. 4 Sub-surface temperature profile from XBTs $\left(13^{\text {th }}-15^{\text {th }}\right.$ June, 2001)

\section{BIOLOGICAL FEATURES DETECTED BY DIFFERENT PLATFORMS}

Fig. 5a shows the weekly chlorophyll concentration (in $\left.\mathrm{mg} / \mathrm{m}^{3}\right)$ obtained from SeaWiFS at a given time $\left(24^{\text {th }}\right.$ October, 2003), and Figs. 5b \& 5c provide the maps of sea level anomaly (SLA) and ADT for $22^{\text {nd }}$ October 2003. High concentrations of chlorophyll are seen in the Scotia Sea, the eastern aperture of the Malvinas Chasm and the surrounding area of FI (Fig. 1). In addition, several possible biological features $(\mathrm{BF})$ are detected. The origin of the one at $52.5^{\circ} \mathrm{S}$, $47^{\circ} \mathrm{W}$ (labeled ' $\mathrm{A}$ ' in Fig. 5) is unknown but could be an independent structure traveling westward from the high chlorophyll concentrations found in the eastern aperture of the Malvinas Chasm. However, the vicinity of the PF flowing eastward seems to preclude this possibility. In the next section we analyze this chlorophyll feature in more detail.

In the area surrounding area the Falkland Islands the SLA is moderately low, ranging between +5 and $+8 \mathrm{~cm}$, whereas in the eastern aperture of the Malvinas Chasm the SLA is negative, ranging between 0 and $-5 \mathrm{~cm}$. In addition, the areas with high chlorophyll concentrations detected in the Scotia Sea also present strong mesoscale variability with panoply of cyclonic and anticyclonic eddies, denoted by low and high SLA respectively. In the eastern and western apertures of DP (far from the areas with high biomass concentrations) we also find many eddies, associated with the ACC.

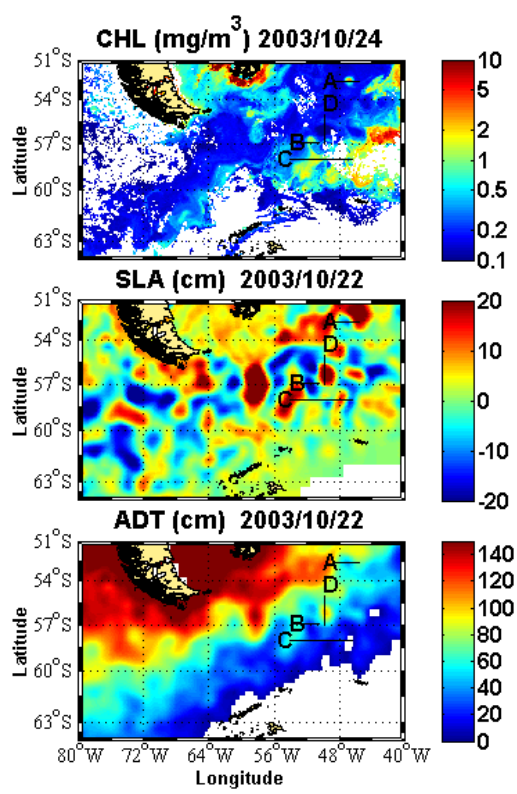

Fig. 5. Weekly chlorophyll (Merged) map (24 $4^{\text {th }}$ October, 2003) with closest map (22 ${ }^{\text {nd }}$ October, 2003) for Sea Level Anomaly (SLA, cm) and Absolute Dynamic Topography (ADT, cm). A, B, C and D represent several eddy features.

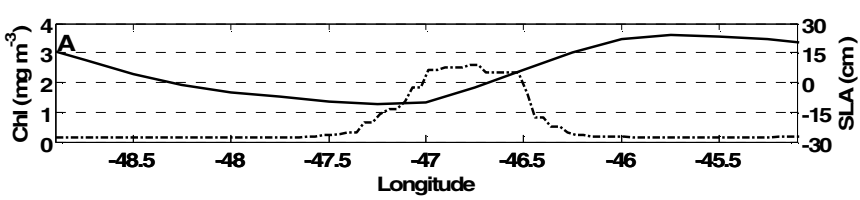

Fig. 6. Longitudinal transect for A section (Fig. 5) of chlorophyll (left yaxis) (dashed-dotted line) and SLA (right y-axis) (solid line) chlorophyll.

We analyze in more detail the relationship between the biological features (BF) and their corresponding signature in the SLA variations. We selected transect A, a zonal section at $52.5^{\circ} \mathrm{S}$ (Fig. 5) and extracted the values for the chlorophyll concentration and SLA (Fig. 6). The peak in chlorophyll 
concentration (up to $3 \mathrm{mg} / \mathrm{m}^{3}$ ) detected at $46.8^{\circ} \mathrm{W}$ is associated with a strong reduction in the SLA, varying from $+15 / 25 \mathrm{~cm}$ in the surrounding waters to almost $-13 \mathrm{~cm}$ in the vicinity of the chlorophyll peak. This SLA feature corresponds to a cyclonic eddy whereas for the same area [6] found biological activity associated with anticyclonic eddies.

The lifetime, trend and size of the BF presented in the previous section, is now analyzed using the quasi-simultaneous maps of ADT and weekly chlorophyll (merged) images. The first evidence of a high biomass concentration is found in the weekly color map of $8^{\text {th }}$ October centered at $53.4^{\circ} \mathrm{S}, 47.8^{\circ} \mathrm{W}$. At the same position at which this peak is found, the closest ADT map shows a well-defined cyclonic eddy. The evolution of the biological eddy is clearly seen in subsequent maps $\left(16^{\text {th }}\right.$ and $24^{\text {th }}$ October and $25^{\text {th }}$ November). The structure is moving northeastward, following the general northeast flow characterized by the PF (Fig. 1). From the color and ADT maps we can deduce the lifetime of the BF, being approximately 2 months (since 22 $2^{\text {nd }}$ September to $25^{\text {th }}$ November, 2003). Finally, the size is about $68 \mathrm{~km}$, assuming a contour value of $0.5 \mathrm{mg} / \mathrm{m}^{3}$ as a threshold and at the moment in which the maximum of chlorophyll is reached (24th October).
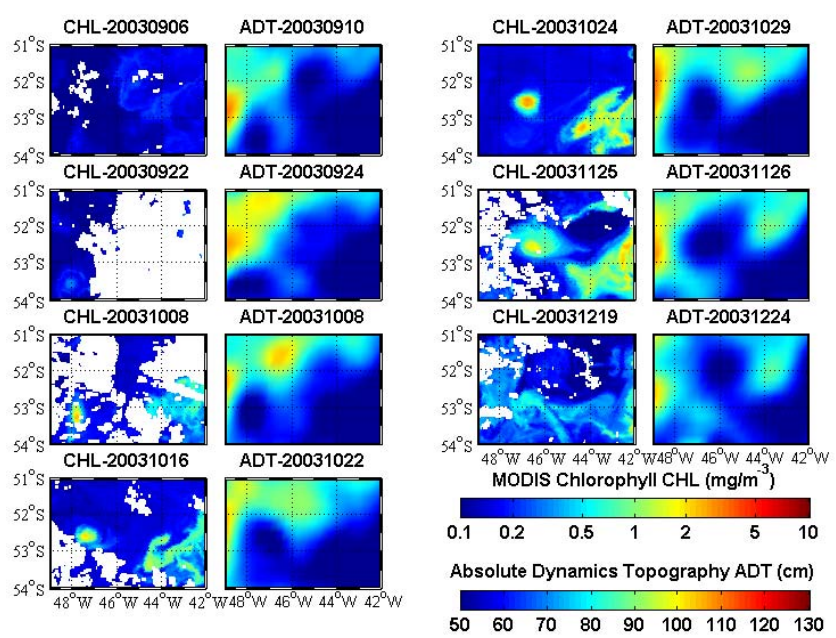

Fig. 7. Series of images showing movement of eddy in altimetry data (a local reduction in ADT) and the corresponding chlorophyll images (MODIS data) for eddy A (Fig 5).

\section{CONCLUSIONS}

In this work, we outlined the capabilities of using a combination of different platforms to characterize the biological features (detected via SeaWIFS and MODIS data) and their signatures in the sea level variations (detected via SLA data), EKE (using zonal/meridional geostrophic velocities) and ADT data. From the results obtained we conclude the following. The climatology of chlorophyll concentration (1998-2005) shows that the areas of high biomass concentration are coincident with areas of low EKE variability (climatology for the period: October 1992 December 2005). We find an exception in the vicinity of the South American coast (Grande Bay), with high chlorophyll concentration and EKE variability. There is a clear correspondence between a cyclonic eddy found in the ADT map of $13^{\text {th }}$ June 2001 (Fig. 3) and a coincident XBT section that shows a cold core at $150 \mathrm{~m}$ (Fig. 4). A series of images for another eddy (Fig. 7) shows northeastward movement in both the altimetry and ocean color signals.

\section{ACKNOWLEDGMENTS}

XBT measurements were made available by the Scripps High Resolution XBT program (http://www-hrx.ucsd.edu). We thank the NASA SeaWiFS and MODIS Project teams for supplying the ocean color images and Aviso for the ADT maps. This work has been done under the auspices of the International Polar Year (IPY), activity ID N: 132 (expression of interest ID $\mathrm{N}^{\circ}$ 567-IRACETSO) and was partially funded by the Spanish Authorities under the $\mathrm{I}+\mathrm{D}+\mathrm{i}$ (Research and Development) Programme, project codes: CGL2004-01473 and VEM2004-08579. The ocean color images have been processed in the Remote Sensing Service at ICMAN-CSIC.

\section{REFERENCES}

[1] Nowlin, W.D.J., T. Whitworth, and R.D. Pilsbury (1977), Structure and transport of the Antarctic Circumpolar Current at Drake Passage from short-term measurements, J. Phys. Oceanogr., 7, 788-810.

[2] Peterson, R.G., W.D.J. Nowlin and T. Whitworth (1982), Generation and evolution of a cyclonic ring at Drake Passage in early 1979, J. Phys. Oceanogr., 12, 712-719.

[3] Challenor, P.G., J.F. Read, R.T. Pollard and R.T. Tokmakian (1996), Measuring Surface Currents in the Drake Passage from altimetry and hydrography, J. Phys. Oceanogr., 26, 2748-2769

[4] Romero, S.I., A.R. Piola, M. Charo and C.A. Eiras Garcia (2006), Chlorophyll-a variability off Patagonia based on SeaWIFS data, J. Geophys. Res., 111, doi: 10.1029/2005JC003244.

[5] Muller-Karger, F.E., R. Varela, R. Thunell, R. Luerssen, C. Hu, and J.J. Walsh (2005), The importance of continental margins in the global carbon cycle, Geophys. Res. Lett., 32, L01602, doi:10.1029/2004GL021346

[6] Glorioso, P.D., A.R. Piola and R.R. Leben (2005), Mesoscale eddies in the Subantarctic Front-Southwest Atlantic, Sci. Mar., 69, 7-15

[7] Moore, J.K., and M.R. Abbott (2000), Phytoplankton chlorophyll distributions and primary production in the Southern Ocean. J. Geophys. Res. 105, 28709-28722.

[8] Moore, J.K., and M.R. Abbott (2002), Surface chlorophyll concentrations in relation to the Antartic Polar Front: seasonal and spatial patterns from satellite observations. J. Mar. Syst, 37, 69-86.

[9] Ducet, N., P.-Y. Le Traon and G. Reverdin (2000), Global high resolution mapping of ocean circulation from TOPEX/Poseidon and ERS-1/2, J. Geophys. Res., 105, 19477-19498.

[10] Pascual, A., Y. Faugère, G. Larnicol and P-Y. Le Traon (2006), Improved description of the ocean mesoscale variability by combining four satellite altimeters, Geophys. Res. Lett., 33, L02611, doi: 10.1029/2005GL024633.

[11] Fu, L.L. and A. Cazenave (2001), Satellite Altimetry and Earth Sciences: a Handbook of Techniques and Applications, International Geophysics Series, Academic Press, 69, 463 pp.

[12] Stammer, D. (1997), Global Characteristics of Ocean Variability Estimated from Regional TOPEX/POSEIDON Altimeter Measurements, J. Phys. Oceanogr., 27, 1743-1769 